Available online at GSC Online Press Directory

GSC Biological and Pharmaceutical Sciences

e-ISSN: 2581-3250, CODEN (USA): GBPSC2

Journal homepage: https://www.gsconlinepress.com/journals/gscbps

(RESEARCH ARTICLE)

\title{
Alterations in oxidative metabolism in liver of female rats: Effects of long-term vitamin A deficiency
}

\author{
Orozco Reina Agustina, Agüero Rocio, Razzeto Gabriela, Gimenez Maria Sofia and Vasquez Gomez Miriam \\ Ester*
}

Department of Biochemistry and Biological Sciences, School of Chemistry, Biochemistry and Pharmacy, National University of San Luis, San Luis, Argentina.

Publication history: Received on 12 March 2020; revised on 15 October 2020; accepted on 20 October 2020

Article DOI: https://doi.org/10.30574/gscbps.2020.13.1.0064

\begin{abstract}
Background: The latest estimate by 5 UN agencies is that 821 million people globally are undernourished, which puts them at risk of vitamin and other nutrient deficiencies. Vitamin A deficiency remains a widespread public health problem among women and children in the developing world the role of vitamin A and its active metabolites in pathways involved in antioxidant protection and in the inhibition of important pathways that promote oxidative stress.

Objectives: Determine if vitamin A deficiency could influence oxidative metabolism in 6-month-old female wistar rats.

Materials and Methods: Determine the concentration of carbonyl proteins, as a marker of protein oxidation; TBARS, as a lipoperoxidation marker; and nitrotyrosine as a marker of oxidative stress dependent on nitric oxide. Quantify the expression of CAT, SOD, eNOS and iNOS in the liver and wistar rats deficient in vitamin A for 6 months.

Results: An increase in the concentration of carbonyl protein and nitrotyrosine in the liver tissue deficient in vitamin A is observed. The expression of SOD, eNOS and iNOS decreased in the group with a private diet of vitamin A. From the regression analysis a positive correlation was established between hepatic retinoic acid levels and gene expression of eNOS, iNOS and SOD. A positive correlation between serum retinoic acid levels and gene expression of eNOS and iNOS was also observed.
\end{abstract}

Conclusions: It is possible to ratify the relationship between the development of stress and vitamin A levels; improving the understanding of hepatic metabolism and its response to the absence of this vitamin.

Keywords: Lipoperoxidation; Nitrotyrosine; Catalase; Superoxide dismutase; Nitric oxide synthetase

\section{Introduction}

Globally, the WHO is frequently quoted as estimating that almost 2 billion people are at risk of micronutrient deficiencies (vitamins and minerals/trace elements) [1]. Amongst these are approximately 125 million preschool children with vitamin A deficiency (VAD), as well as subpopulations at risk of deficiencies of folate, thiamin, vitamin B12, niacin, other $B$ vitamins, and vitamin D [1, 2]. Some stages of life present a higher risk of deficiency than others: risks are higher in pregnant women, children (from conception to young childhood), adolescents, and the elderly. The latest estimate by 5 UN agencies is that 821 million people globally are undernourished, which puts them at risk of vitamin and other micro-

\footnotetext{
${ }^{*}$ Corresponding author: Vasquez Gomez Miriam Ester

Department of Biochemistry and Biological Sciences, School of Chemistry, Biochemistry and Pharmacy, National University of San Luis, San Luis, Argentina..

Copyright (C) 2020 Author(s) retain the copyright of this article. This article is published under the terms of the Creative Commons Attribution Liscense 4.0.
} 
and macro-nutrient deficiencies [3, 4]. VAD remains a widespread public health problem among women and children in the developing world [5], and it increases morbidity and mortality due to increased susceptibility to infection [6].

Vitamin A is a non-enzymatic antioxidant necessary for the body's redox balance [7], although its action is varied and has extensive intervention in various metabolic pathways, its role as a protector against damage caused by reactive oxygen species through the activation of transcription of antioxidant genes such as the Glutathione s-transferase (GPX) [8], and superoxide dismutase (SOD) [9]. On the other hand, it is known that it is capable of preventing lipoperoxidation of membranes by acting as a sequestrant of various free radicals [10]. In 8-week VAD rats, a decrease in hepatic retinol concentration and a significant increase in Thiobarbituric Acid-Reactive Substances (TBARS) levels were found [11]. An important mediator of oxidative stress and inflammation is the release of nitric oxide (NO) as a result of the possible activation of some or several isoforms of nitric oxide synthase (NOS): inducible (iNOS), endothelial (eNOS) or neuronal (nNOS); each of them activated in a site-specific depending on the tissue. Vitamin A inhibits the expression of iNOS in murine mesangial cells promoted by the stimulation of these with all-trans retinoic acids (at-RA), observing this as an effective anti-inflammatory strategy [12]. Another study on peripheral blood mononuclear cells of patients with rheumatoid arthritis, an autoimmune disease characterized by producing an increase in NO release due to increased expression of iNOS, an effect that was attenuated by stimulation with at-RA. In this same study, it was determined that at-RA also inhibited nuclear translocation of NFKB, a master regulator of pro-inflammatory mechanisms [13].

Another study demonstrated that VAD induces a pro-oxidant environment and inflammation in rat aorta $[14,15,16]$. All these results show the role of vitamin A and its active metabolites in pathways involved in antioxidant protection and in the inhibition of important pathways that promote oxidative stress.

In our laboratory we have observed that vitamin A exerts antioxidant action and its deficiency increases the values of oxidative stress markers and alters the metabolism of lipids in liver, heart, aorta in deficient male rats of 3 months [15, $17,18]$.

These antecedents show that VAD could influence the metabolism of different organs. Therefore, a 6-month-old female wistar rats were studied in vivo, if VAD predisposes to changes in oxidative stress parameters.

\section{Material and methods}

\subsection{Animals and diets}

Female Wistar rats, bred in our animal facilities (IMIBIO, National University of San Luis, Argentina), were weaned at 21 days old and immediately randomly assigned to either the experimental group (standard diet, devoid of vitamin A [VAD group]), the control (CO) group (standard diet with $4000 \mathrm{IU}$ of vitamin A [8 $\mathrm{mg}$ retinol as retinyl palmitate] per kilogram of diet) or refeed group (REF). The experimental period was 6 months for VAD and CO and 5 months with VAD diet and 30 days with control diet for the REF group. REF group was used to study the reversibility of the possible changes caused by the vitamin deficiency. Diets, mineral mix and vitamin mix were prepared according to the AIN-93 for laboratory rodents [19]. The rats were kept in a $21^{\circ} \mathrm{C}-23{ }^{\circ} \mathrm{C}$ controlled environment with a 12-hours light:dark cycle. They were given free access to food and water throughout the entire experimental period. After the entire treatment period, 4 rats from each group (CO, VAD and REF) were euthanized by $\mathrm{CO} 2$ inhalation. The blood was collected without anticoagulant in order to obtain the serum. For this purpose, the samples were washed with $\mathrm{H} 2 \mathrm{O}$ at $37^{\circ} \mathrm{C}$ for $20 \mathrm{~min}$. The serum was then centrifuged 2 times at $3000 \mathrm{rpm}$ for $10 \mathrm{~min}$. Then the liver was separated. The tissue fractions were maintained at $-70{ }^{\circ} \mathrm{C}$. The samples for the determination of retinol were separated and protected from light, in order to decrease the photoisomerization of vitamin A. We followed the general guidelines for the care and use of laboratory animals recommended by the Animal Care Committee of the National University of San Luis.

\subsection{Retinol concentration analyses}

The retinol concentration was determined by the modified technique Neeld and Pearson [20]. The homogenates of liver or mammary gland and serum, was treated with $1 \mathrm{ml}$ of $95 \%$ ethanol to precipitate proteins, and $1.5 \mathrm{ml}$ of petroleum ether to extract vitamin A and carotenoids. It was centrifuged at $3000 \mathrm{rpm}$ for 10 minutes at $37^{\circ} \mathrm{C}$. The supernatant was read at $450 \mathrm{~nm}$, corresponding to the absorbance of carotenes. Then was dried in an oven at $37^{\circ} \mathrm{C}$ and the residue was taken up in $50 \mu \mathrm{l}$ of chloroform, $50 \mu \mathrm{l}$ of acetic anhydride and $500 \mu \mathrm{l}$ of TFA (Trifluoroacetic) is then added with vigorous stirring to $620 \mathrm{~nm}$ absorbance and read within 30 seconds. In parallel a standard curve of vitamin A and carotenes process was made. Because the $\beta$-carotene reacts with TFA, the results were corrected after reading the absorbance at $450 \mathrm{~nm}$ and calculate the corresponding correction factor [19]. 


\subsection{Preparation of tissue homogenate}

Four livers per experimental group were homogenized separately in $150 \mu$ RIPA buffer (Thermo Fisher Scientific Inc., Waltham, MA, USA) according to the manufacturer's instructions. Tissue homogenates were centrifuged at $14,000 \times \mathrm{g}$ for $15 \mathrm{~min}$ at $4{ }^{\circ} \mathrm{C}$ to remove nuclei and cell debris. The pellets were discarded whereas the supernatants were collected and used to determine the concentration of protein carbonyls and thiobarbituric acid reactive substances (TBARS) and nitrotyrosine. The total protein concentration in tissue homogenates was measured by the Biuret method.

\subsection{TBARS}

Measurement of lipid peroxidation TBARS were determined according to the method described by Draper and Hadley [21]. The TBARS assay measures malondialdehyde (MDA) production from lipid hydroperoxides. A calibration curve was performed using 1,1,3,3-tetramethoxypropane as standard. TBARS were determined by the absorbance at $535 \mathrm{~nm}$ and were expressed as $\mu \mathrm{mol}$ of MDA per milligram of total proteins ( $\mu \mathrm{mol} \mathrm{MDA} / \mathrm{mg}$ protein)

\subsection{Measurement of protein oxidation}

As a marker of protein oxidation, protein carbonyls were determined by ELISA following the method of Winterbourn and Buss [22], with some modifications. Briefly, tissue homogenates were derivatized to 2,4-dinitrophenylhydrazone by reaction of carbonyl groups in oxidized proteins with 2,4-dinitrophenylhydrazine in $2 \mathrm{M} \mathrm{HCl} .10 \mu \mathrm{l}$ of the derivatized or nonderivatized sample were added to $190 \mu \mathrm{l}$ of $0.1 \mathrm{M}$ bicarbonate buffer, $\mathrm{pH}$ 9.6, in clear 96-well microplates (Corning Incorporated, Corning, NY, USA) and incubated overnight at $4{ }^{\circ} \mathrm{C}$. After washing with PBS (0.05\%) Tween-20 (5\%) and blocking in PBS at $37^{\circ} \mathrm{C}$ for $1 \mathrm{~h}$, the microplates were incubated with $50 \mu \mathrm{l}$ of rabbit polyclonal anti-dinitrophenyl antibody (1:2000 dilution; Thermo Fisher Scientific Inc., Waltham, MA, USA) for $1 \mathrm{~h}$ at $37^{\circ} \mathrm{C}$. After three washes, $50 \mu \mathrm{l}$ of goat anti-rabbit IgG-HRP conjugate (1:10,000 dilution; Jackson Immuno Research Laboratories, West Grove, PA, USA), was added to each well and incubated for $1 \mathrm{~h}$ at $37^{\circ} \mathrm{C}$. Finally, immunocomplexes were quantified using TMB. The oxidation reaction of the substrate was stopped with $2 \mathrm{M}$ sulfuric acid and the absorbance was measured at $450 \mathrm{~nm}$ using a TECAN microplate reader (Infinite M200 PRO, Research Triangle Park, NC, USA). The results were expressed as nmol of carbonyl per milligram of total proteins (nmol/mg protein).

\subsection{Nitrotyrosine}

The nitrotyrosine is a NO-dependent oxidative stress marker [23]. Distilled water is used throughout for preparation of solutions. The following reagents and solutions were used for experiments: sodium nitrite, phosphate buffered saline (PBS), pH 7.4 - 7.5, sodium hydrosulfite (Brueggemann Chemical, Heilbronn, Germany), BioRad Protein Assay Dye Reagent Concentrate (Bio-Rad Laboratories, Munich, Germany), primary antibody anti-nitrotyrosine (1:2000 dilution; Thermo Fisher Scientific Inc., Waltham, MA, USA) and secondary antibody goat anti-rabbit IgG, HRP-conjugate (1:10,000 dilution; Jackson Immuno Research Laboratories, West Grove, PA, USA). Citric acid-monohydrate, hydrogen peroxide (30\%), potassium chloride, potassium dihydrogen phosphate, sodium chloride, di-sodium hydrogen phosphate, bovine serum albumin fraction $\mathrm{V}$ (fatty acid free), tri-sodium phosphate-dodecahydrate, sodium dihydrogen phosphatemonohydrate, Tween 20, hydrochloric acid (37\%) and sodium hydroxide were all purchased from Carl Roth (Karlsruhe, Germany). o-pheneylendiamin dihydrochloride, tablet, $60 \mathrm{mg}$ substrate and 3-nitro-L-tyrosine were purchased from Sigma - Aldrich (Steinheim, Germany).

\subsection{RNA Isolation and RT-PCR Analysis}

Total RNA was isolated from 150/200 mg of liver using the guanidinium isothiocyanate-acid phenol method as modified by Puissant and Houdebine [24]. $10 \mu \mathrm{g}$ of total RNA were reverse transcribed (RT) at $37^{\circ} \mathrm{C}$ using random hexamer primers and Moloney murine leukemia virus retrotranscriptase (Invitrogen-Life Technologies, Buenos Aires, Argentina) in a $20 \mu \mathrm{L}$ reaction mixture. The RNA was first denatured at $70{ }^{\circ} \mathrm{C}$ for $5 \mathrm{~min}$ in the presence of $2.5 \mu \mathrm{g}$ of random hexamer primers (Invitrogen). For the subsequent RT reaction the following mixture was added: RT buffer [50 mM TriseHCl (pH8.4), $75 \mathrm{mM} \mathrm{KCl,} 3$ mM MgCl2], 0.5 mM dNTPs, 5 mM DTT, 200 units M-MLV Reverse Transcriptase. The reaction was incubated at $37^{\circ} \mathrm{C}$ for $50 \mathrm{~min}$, and then the reaction was inactivated by heating at $70{ }^{\circ} \mathrm{C}$ during $15 \mathrm{~min}$. The cDNA was stored at $20^{\circ} \mathrm{C}$. The mRNA levels of CAT, SOD, iNOS, eNOS and S16 were estimated by RT-PCR using ratspecific primers and reaction conditions described in Table 1. The PCR reactions were performed using a Biorad Thermocycler in a final volume of $20 \mu \mathrm{L}$. The reaction mixture consisted of $2 \mu \mathrm{L}$ of $10 \mathrm{X}$ PCR Buffer, $1 \mu \mathrm{L}$ of $50 \mathrm{mM} \mathrm{MgCl} 2$, $0.4 \mu \mathrm{L}$ of $10 \mathrm{mM}$ dNTP Mix (Invitrogen), $0.25 \mu \mathrm{L}$ of $5 \mathrm{U} / \mathrm{mL}$ Taq DNA Polymerase (Invitrogen), $0.1 \mu \mathrm{L}$ of each $2.5 \mathrm{mM}$ primer (forward and reverse primers) and $11 \mu \mathrm{L}$ of diluted cDNA. The PCR reactions were initiated with 5 min incubation at $95^{\circ} \mathrm{C}$, followed by 40 cycles of $95^{\circ} \mathrm{C}$ for $60 \mathrm{~s}, 60 \mathrm{~s}$ at the annealing temperatures shown in Table 1 and 72 ${ }^{\circ} \mathrm{C}$ for $60 \mathrm{~s}$. Each PCR run included a notemplate control and a sample without RT. All measurements were performed in duplicate. RNA samples were assayed for DNA contamination by performing the different PCR reactions without prior 
RT. Relative levels of mRNA were normalized to the S16 reference gene. The resultant products obtained after PCR were separated by electrophoresis on $2 \%$ agarose gel containing GelRed. The image was visualized and photographed under UV transillumination.

Table 1 PCR primers and conditions.

\begin{tabular}{|l|l|l|l|l|l|}
\hline $\begin{array}{l}\text { Prime } \\
\mathbf{r}\end{array}$ & Primer sense $\mathbf{( 5}^{\prime} \mathbf{- 3}^{\prime} \mathbf{)}$ & Primer Antisense (5'- 3') & Tm & $\begin{array}{l}\text { Fragment } \\
\text { size }\end{array}$ & $\begin{array}{l}\text { Concentrati } \\
\text { on }\end{array}$ \\
\hline eNOS & $\begin{array}{l}\text { CGAGATATCTTCAGTCCCAAG } \\
\text { C }\end{array}$ & GTGGATTTGCTGCTCTGTAGG & $56^{\circ} \mathrm{C}$ & $164 \mathrm{bp}$ & $\begin{array}{l}\text { NM_021838. } \\
2\end{array}$ \\
\hline iNOS & $\begin{array}{l}\text { GCATGGACCAGTATAAGGCAA } \\
\text { GCA }\end{array}$ & $\begin{array}{l}\text { GCTTCTGGTCGATGTCATGAGCA } \\
\text { A }\end{array}$ & $56^{\circ} \mathrm{C}$ & $222 \mathrm{bp}$ & $\begin{array}{l}\text { NM_010927. } \\
4\end{array}$ \\
\hline CAT & CGACCGAGGGATTCCAGATG & ATCCGGGTCTTCCTGTGCAA & $60^{\circ} \mathrm{C}$ & $175 \mathrm{bp}$ & BC081853 \\
\hline SOD & AGCTGCACCACAGCAAGCAC & TCCACCACCCTTAGGGCTCA & $60^{\circ} \mathrm{C}$ & $191 \mathrm{bp}$ & S41066 \\
\hline S16 & TCCAAGGGTCCGCTGCAGTC & CGTTCACCTTGATGAGCCCATT & $599^{\circ} \mathrm{C}$ & $100 \mathrm{bp}$ & $\begin{array}{l}\text { NM_013647. } \\
2\end{array}$ \\
\hline
\end{tabular}

Tm, melting temperature.

\subsection{Statistical Analysis}

Results were expressed as mean values with their standard device (SD). Statistical comparisons were made transversely between different dietary groups. The statistical significance between groups was determined by one-way ANOVA and the differences between the individual means were analyzed using Tukey's post hoc test. Differences having P values lower than 0.05 were considered to be statistically significant. Data analysis was done using the Graphpad prism 5 software. The images were taken with digital camera and the images analyzed with Image J software.

\section{Results}

\subsection{Biomarkers of oxidative stress: protein carbonyl, TBARS and Nitrotyrosine levels}

The VAD and REF groups increase the protein carbonyl content in liver tissue, as compared to the CO group (p<0.01) (Figure 1A). In addition, no significant modification in TBARS concentration in liver was observed with the different treatments (Figure 1B). An increase in nitrotyrosine content was observed in the VAD and REF groups, with respect to the CO group $(\mathrm{p}<0.05)$ (Figure 2).
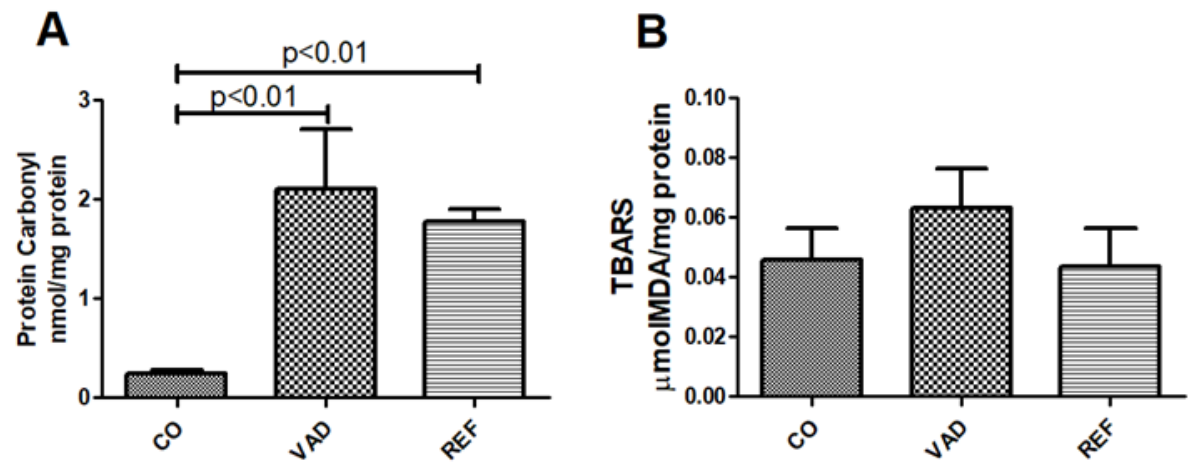

Figure 1 Biomarkers of oxidative stress. A) protein carbonyl content, expressed as nmol/mg protein; Results are expressed as mean \pm SD $(n=4)$. B) TBARS content, expressed as $\mu$ mol MDA/mg protein. Results are expressed as mean \pm SD $(n=4)$. TBARS: thiobarbituric acid reactive substances. 


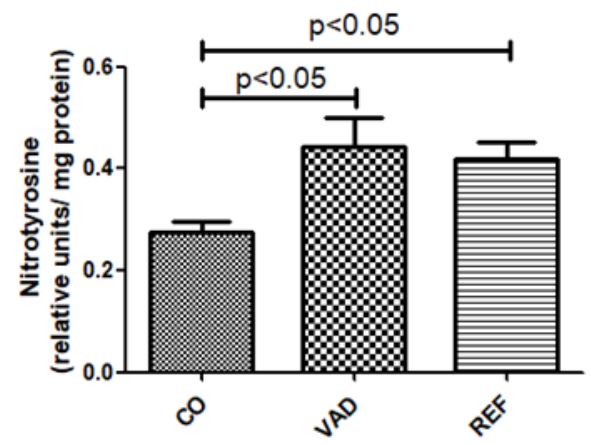

Figure 2 Nitrotyrosine content in liver, expressed as relative units of nitrotyrosine/mg protein. Results are expressed as mean $\pm \operatorname{SD}(n=4)$.

\subsection{Effect of VAD on CAT mRNA expression in liver}

The expression of CAT in liver was determined. Figure 3 shows the expression of CAT in liver in the different experimental groups. No difference was observed in the expression of the different experimental groups.

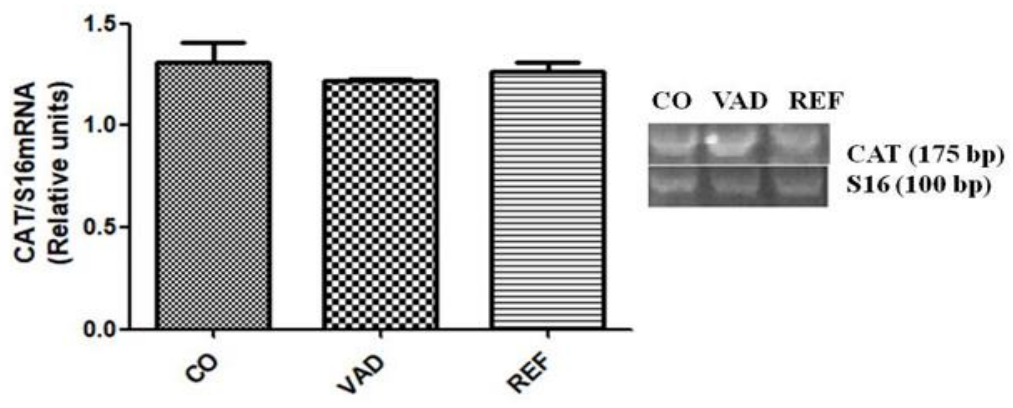

Figure 3 Expression of CAT in liver by RT-PCR in the different experimental groups. A) Semi-quantitative analysis of CAT expression. B) Gel representative of the gene expression of CAT in the different experimental groups. Expression of CAT was performed using specific primers, and was adjusted for expression of the constitutive gene S16, as described in Materials and Methods. Representative image of the agarose gel of CAT (175 bp) and S16 (100 bp) products.

\subsection{Effect of VAD on SOD mRNA expression in liver}

The expression of SOD in liver was determined. Figure 4 shows the expression of SOD in liver in the different experimental groups, where a decrease in expression was observed in the VAD and REF groups with respect to the CO group $(\mathrm{p}<0.001)$.

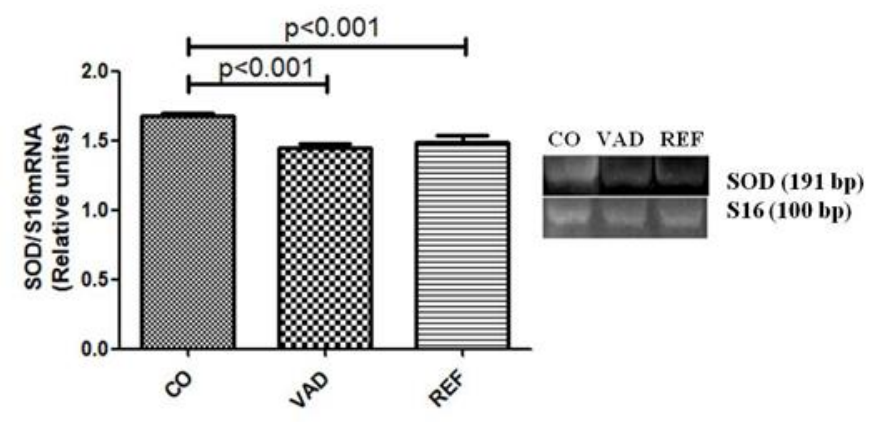

Figure 4 Expression of SOD in liver by RT-PCR in the different experimental groups. A) Semi-quantitative analysis of SOD expression. B) Gel representative of the gene expression of SOD in the different experimental groups. Expression of SOD was performed using specific primers, and was adjusted for expression of the constitutive gene S16, as described in Materials and Methods. Representative image of the agarose gel of SOD (191 bp) and S16 (100 bp) products. 


\subsection{Effect of VAD on eNOS mRNA expression in liver}

The expression of eNOS in liver was determined. Figure 5 shows the expression of eNOS in liver in the different experimental groups, where a decrease in expression is observed in the group with deprived diet of vitamin A (VAD group) $(\mathrm{p}<0.05)$.

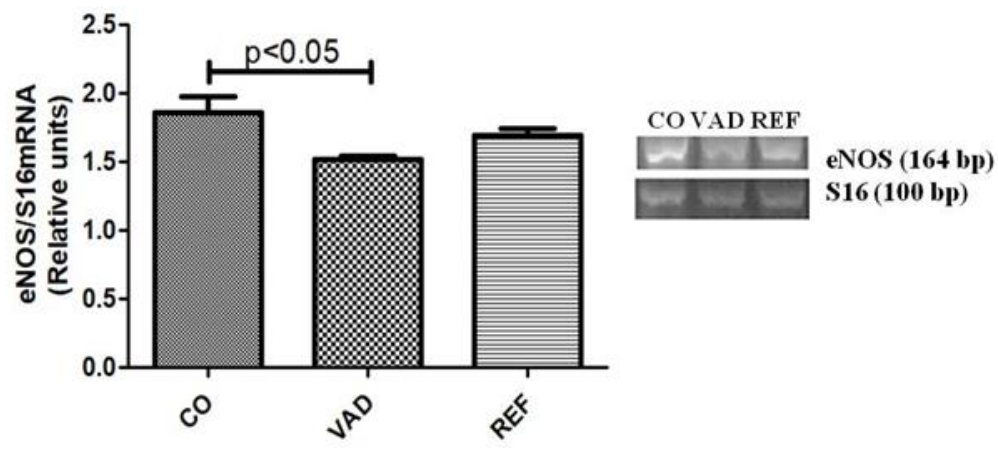

Figure 5 Expression of eNOS in liver by RT-PCR in the different experimental groups. A) Semi-quantitative analysis of eNOS expression. B) Gel representative of the gene expression of eNOS in the different experimental groups. Expression of eNOS was performed using specific primers, and was adjusted for expression of the constitutive gene S16, as described in Materials and Methods. Representative image of the agarose gel of eNOS (164 bp) and S16 (100 bp) products.

\subsection{Effect of VAD on iNOS mRNA expression in liver}

Expression of iNOS was determined. Figure 6 shows iNOS expression in liver in the different experimental groups, where a decrease in expression in the VAD group and an increase after supplementation was observed $(p<0.0001)$. The 30-day diet with enough vitamin A diet was sufficient for the REF group to return to the control values.

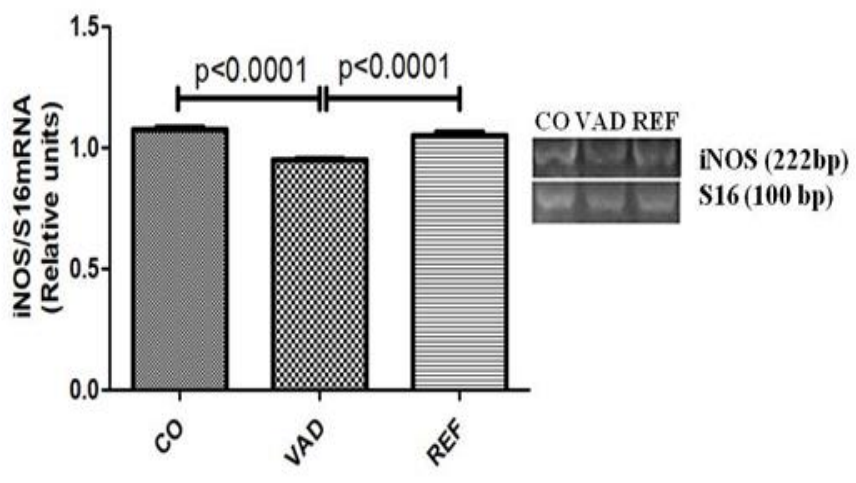

Figure 6 Expression of iNOS in liver by RT-PCR in the different experimental groups. A) Semi-quantitative analysis of iNOS expression. B) Gel representative of the gene expression of iNOS in the different experimental groups. Expression of iNOS was performed using specific primers, and was adjusted for expression of the constitutive gene S16, as described in Materials and Methods. Representative image of agarose gel for iNOS (222 bp) and S16 (100 bp) products.

\subsection{Linear regression analysis between biochemical and molecular parameters}

\subsubsection{Correlation between levels of retinoic acid and gene expression of eNOS, iNOS, SOD and CAT.}

With the data of RA in liver published by Vasquez et al. [17], the degree of relationship with the expression levels of the genes studied was determined by means of linear regression analysis whose significant results are shown in the Figure 7. From the regression analysis it was possible to establish a positive correlation between hepatic RA levels and gene expression of eNOS, iNOS and SOD. 


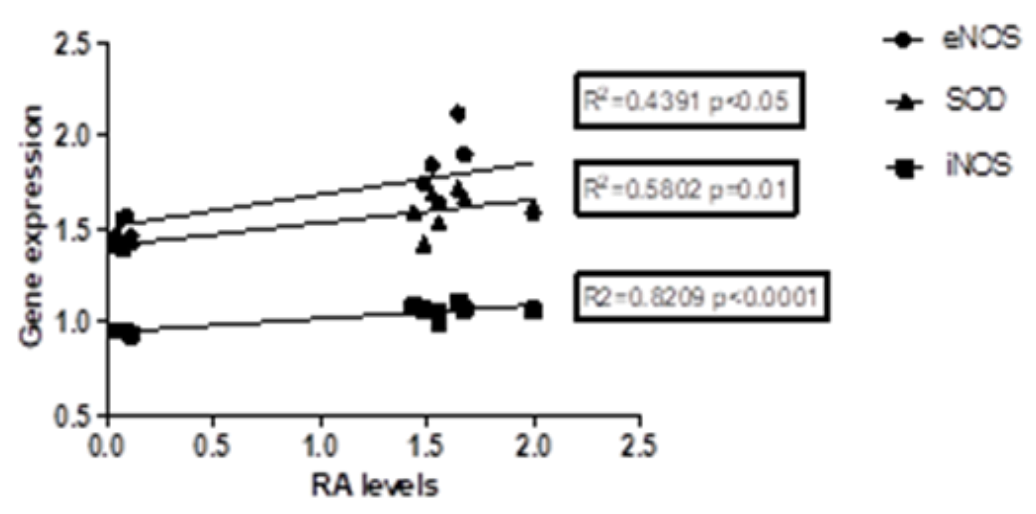

Figure 7 Relationship between liver RA and gene expression of eNOS, iNOS and SOD in VAD model. In each graph, the values of " $p$ " obtained from the statistical analysis for each regression are described in the respective lines, establishing $\mathrm{p}<0.05$ as significant, the values of "R square" $\left(\mathrm{R}^{2}\right)$ are also described as a measure of the goodness of fit of the data to their respective lines and as a parameter to establish the degree of relationship between the variables.

\subsubsection{Correlation between RA levels of serum and gene expression of eNOS and iNOS.}

With the serum RA data published by Vasquez et al. [17], we wanted to determine the degree of relationship with the levels of expression of the genes studied by means of linear regression analysis whose significant results are shown in Figure 8. A positive correlation between serum RA levels and gene expression of eNOS and iNOS could be established, with no correlation with CAT and SOD (data not shown).

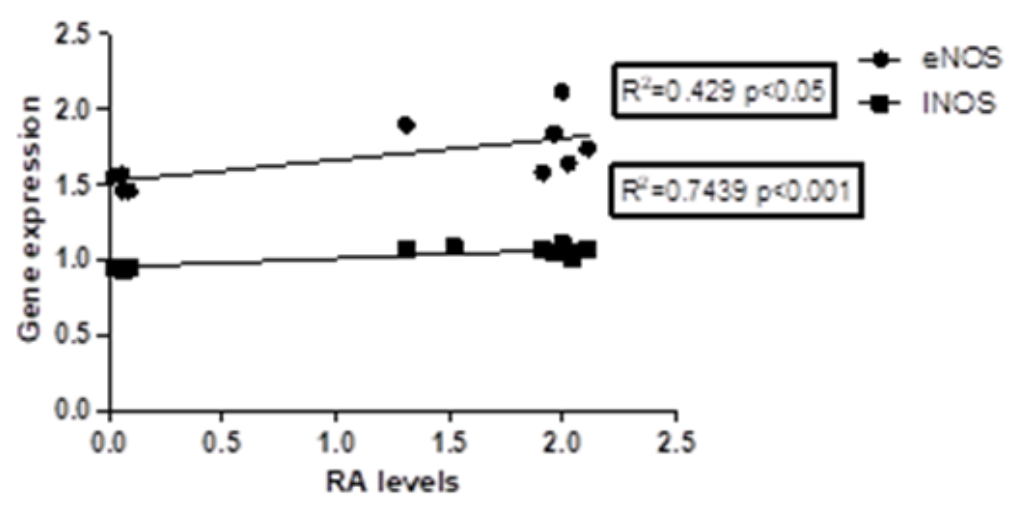

Figure 8 Relationship between Serum RA and eNOS and iNOS gene expression in VAD model. In each graph, the values of " $p$ " obtained from the statistical analysis for each regression are described in the respective lines, establishing $p<0.05$ as significant, the values of "R square" $\left(\mathrm{R}^{2}\right)$ are also described as a measure of the goodness of fit of the data to their respective lines and as a parameter to establish the degree of relationship between the variables.

\subsubsection{Correlation between nitrotyrosine levels of liver and gene expression of SOD.}

With the nitrotyrosine levels of liver, we wanted to determine the degree of relationship with the levels of expression of SOD studied by means of linear regression analysis whose significant results are shown in Figure 9. A negative correlation between nitrotyrosine levels and gene expression of SOD could be established. 


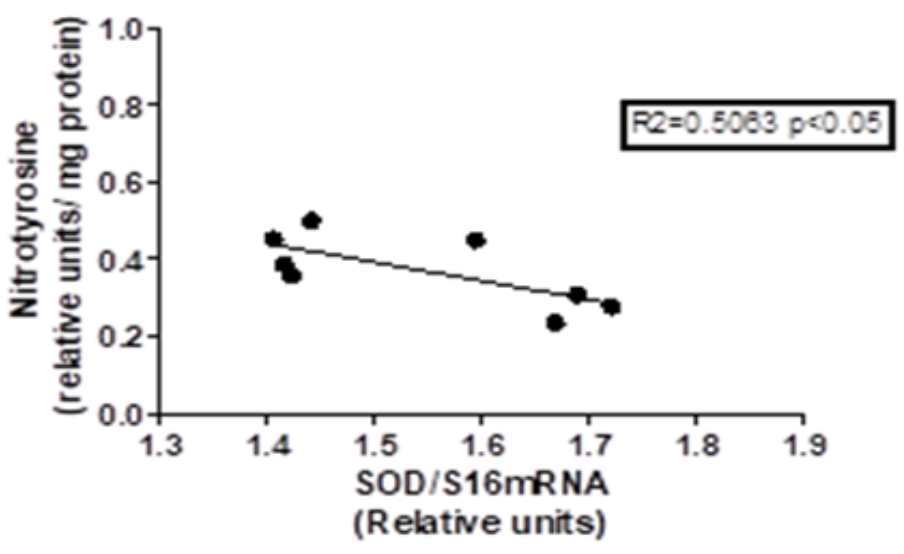

Figure 9 Relationship between nitrotyrosine levels and gene expression of SOD of liver in VAD model. In each graph, the values of " $p$ " obtained from the statistical analysis for each regression are described in the respective lines, establishing $\mathrm{p}<0.05$ as significant, the values of "R square" $\left(\mathrm{R}^{2}\right)$ are also described as a measure of the goodness of fit of the data to their respective lines and as a parameter to establish the degree of relationship between the variables.

\section{Discussion}

The protective action against oxidative damage of vitamin A and its metabolites through the activation of genomic and non-genomic mechanisms is well known. To evaluate oxidative stress there are different biomarkers, among them: carbonyls, TBARS and nitrotyrosine [25]. The most prominent biomarkers that reflect oxidative stress are protein carbonyls, that is, plasma proteins containing oxidized residues such as aldehydes and ketones; 3-nitrotyrosine, a marker for nitrated proteins; and MDA, a lipid peroxidation product derived from the oxidative breakdown of polyunsaturated fatty acids [26]. There are no publications, to date, on the effect of long-term VAD in liver on the oxidative stress process. The assessment of oxidative damage to proteins can be achieved by using the carbonyl test and the nitrotyrosine is a NO-dependent oxidative stress marker [25, 27]. The patients with abetalipoproteinemia have malabsorption and a deficiency of fat-soluble vitamins, specifically, vitamins E and A; when supplemented with vitamin A there is no change in carbonyl levels [28]. Vitamin A supplementation increased mitochondrial superoxide anion radical (02-) production and induced lipid peroxidation, protein carbonylation and nitration, and oxidation of protein thiol groups in mitochondrial membranes isolated from rat cerebral cortex, cerebellum, substantia nigra, striatum, frontal cortex, and hypothalamus [29]. In long-term VAD rats an increase in the levels of cabonyl and nitrotyrosine was observed with respect to the control group, which could not be reversed with vitamin A supplementation (Figure $1 \mathrm{~A}$ and 2).

It has been reported that pro-oxidant effects occur in male rats with 3-month VAD [17], in heart [18]. An increase in TBARS levels was observed in aorta [14]. It has been shown that the lungs of rats with VAD increased TBARS levels [30]. A decrease in hepatic retinol concentration and a significant increase in TBARS levels were found [11]. Barber et al. [31] reported that in liver mitochondria, MDA levels were high compared to control rats. Moreover, it is known that retinol is able to prevent lipoperoxidation of membranes by acting as a sequestrant of various free radicals [10]. In female VAD long-term rats, no change in TBARS levels was observed in the different experimental groups (Figure 2B).

Oxidative stress may be the result of alterations in the antioxidant mechanism, such as the decrease in activity or expression of enzymes such as CAT and SOD. Antioxidant genes such as the GPX gene [8] and SOD [9] have been activated by the action of retinoids. In aorta it was reported that the activities of SOD, GPX and CAT were significantly reduced in the VAD group, contributing to oxidative damage [14]. A decrease in CAT activity in plasma and liver microsomes has also been observed in retinol-deficient rats [32]. Other authors noted that in rats deficient in retinol, an increase in lipid peroxidation and a decrease in the activity of CAT in plasma and liver were found [33,34]. In rat hippocampus, VAD significantly reduces levels of CAT and GPX mRNA, however, no effect on SOD expression was observed [35]. The same authors reported that the refeed with vitamin A, for 15 days, restores the levels of transcription of CAT and GPX to the control values. Moreover, rats with VAD for 2 months showed no difference in the levels of SOD and CAT in the heart, while in the liver SOD decreased; which was accompanied by lipoperoxidation in the heart, but not in the liver [36]. The administration of at-Ral significantly increases the production of intracellular oxygen reactive species and regulates the expression of Nrf-2 mRNA [37], which is the master regulator of the expression of the antioxidant genes CAT, SOD and GPX in response to cellular oxidative stress. RA has been shown to regulate upward 
Nrf-2 in neuronal cells [38]. In mice, RA increases nuclear accumulation of Nrf2 and causes lipid peroxidation [39]. James et al [40] demonstrated that the administration of vitamin A and RA improves the development and lung function associated with a reduction in DNA damage and protein oxidation accompanied by reductions in nuclear Nrf2. The administration of vitamin A activates the Nrf2 / ARE pathway to exert protective effects on liver damage [40]. On the basis of the bibliography consulted, contradictory results are observed regarding the consequences of VAD, depending on the model and the tissue used. In our experimental model, no difference was observed in CAT expression; and if a decrease in SOD expression but a month's refeed does not seem to be sufficient to restore the normal expression levels of this enzyme (Figure 3 and 4). This decrease in SOD expression could lead the liver tissue to a process of oxidative stress due to a lack of antioxidant response through the Nrf2 / ARE pathway. These results are consistent with the results of works where it has been shown that RA and atRA exerts their function as an antioxidant and anti-apoptotic agent through the maintenance of SOD levels [9]. When the specific activity of both SOD and GPX decreases, this results in an accumulation of hydrogen peroxide that stimulates a cascade of lipid peroxidation and oxidation protein processes [42]. The results of our model agree with a decrease in the expression of SOD mRNA and an increase in protein oxidation, generating an environment of oxidative stress.

An important mediator of the oxidative stress and inflammation process is the release of NO as a result of the activation of iNOS and / or eNOS in the tissues or of nNOS in neuronal tissues through the activation of NF- $\kappa \beta$, one of the regulators masters of inflammatory mechanisms. In VAD pro-oxidant effects have been reported due to this state, such as the presence of oxidative damage. An increase in the expression of eNOS and iNOS was reported in male aorta [14]. Although the presence of oxidative stress in the liver has already been demonstrated by Anzulovich et al. [17] in a VAD model with three-month-old male rats, enzymes related to the production of reactive nitrogen species such as eNOS and iNOS have not been evaluated in liver tissue in any long-term VAD model. In our model, there was a marked decrease in the levels of both eNOS and iNOS in the VAD group, with recovery being observed with refeed only in iNOS (Figure 7 and 8). High concentrations of NO have been shown to regulate their own production in a negative way, modulating the expression of iNOS, but not modulating the expression of eNOS [43]. Nitrotyrosine levels are accepted as a reliable marker for the production of peroxynitrite, because peroxynitrite has been shown to produce detectable amounts of nitrated plasma proteins $[44,45]$. Nitric oxide, responsible for blood flow, leads to increased peroxynitrite formation in the presence of superoxide [26]. In serum of 3-month VAD rats, an increase in NO was observed [14]. It is well known that eNOS is constitutively expressed in hepatic endothelial and vascular tissue, while iNOS is overexpressed in the presence of oxidative stress and inflammation by NFkb regulation. This transcription factor is positively regulated in the VAD [46]. In the case of eNOS, it has recently been proven that its expression is under the control of the PPAR $\alpha$ transcription factor [47], which is negatively regulated in the liver at three months of VAD [18]. On the contrary, in heart VAD, PPAR $\alpha$ is increased, as well as the expression of eNOS and iNOS [48]. All these results would imply that downregulation of eNOS gene expression may be mainly due to the low activation of PPAR $\alpha$ during VAD. While downregulation of iNOS can occur in response to two factors: 1) at high concentrations of NO, since we can show an increase in nitrotyrosine levels, which is a NO-dependent marker (Figure 2); and 2) to a greater formation of peroxynitrite in the presence of superoxide; The superoxide may be elevated in the long-term VAD liver due to a reduced antioxidant capacity due to lower SOD expression (Figure 4), correlation that can be seen in Figure 9.

To establish the relationship between serum RA levels and liver levels with the gene expression levels of the enzymes studied, the corresponding regression and correlation analyzes were performed. It was observed that the expression of eNOS and iNOS respond proportionally to serum and liver RA levels (Figure 7 and 8). SOD expression correlates with liver RA levels (Figure 7). Demonstrating a direct effect of the long-term VAD on mRNA expression of these enzymes.

\section{Conclusion}

The results obtained in this work confirm the importance of vitamin A in homeostatic maintenance and tissue protection as it is key to the control of cellular redox balance as a potent antioxidant and anti-inflammatory. It is possible to ratify the relationship between the development of stress and vitamin A levels; and that through detailed knowledge of its mechanisms, a better understanding of liver metabolism and its response to the absence of vitamin A will be possible. With this, establishing effective therapies, where RA seems to be key to the maintenance of homeostasis and liver health. 


\section{Compliance with ethical standards}

\section{Acknowledgments}

This research was supported by grants from the National University of San Luis (PROICO 02-0418).

\section{Disclosure of conflict of interest}

The authors declare no conflict of interests with respect to the present paper.

\section{Statement of ethical approval}

This study has the approval of the Institutional Committee for Animal Care and Use (CICUA) of the National University of San Luis.

\section{References}

[1] Bailey RL, West KP Jr, Black RE. The epidemiology of global micronutrient deficiencies. Ann Nutr Metab. 2015; 66 (Suppl 2): 22-33.

[2] Darnton-Hill I. Chapter 2, Prevalence, causes and consequences of micronutrient deficiencies. In Mannar V Hurrell R, editors. Food fortification in a globalized world. London, UK: Academic Press/Elsevier. 2017; 13-28.

[3] FAO, IFAD, UNICEF, WFP, WHO. The state of food security and nutrition in the world [Internet]. Rome, Italy: Food and Agricultural Organization of the UN. 2018.

[4] Darnton-Hill I. Public health aspects in the prevention and control of vitamin deficiencies. Curr Dev Nutr. N2019; 3(9): nzz075.

[5] Klemm R, Palmer A, Greig A, Engle-Stone R and Dalmiya N. A changing landscape for vitamin a programs: implications for optimal intervention packages, program monitoring, and safety. Food and Nutrition Bulletin. 2016; 1-12.

[6] Stephensen CB. Vitamin a, infection, and immune function. The Annua Review of Nutrition. 2001; 21: 167-192.

[7] Rao AV, Rao LG. Carotenoids and human health. Pharmacol res. 2007; 55(3): 207-16.

[8] Lo H W, F Ali-Osman. Genomic cloning of hGSTP1*C, an allelic human Pi class glutathione S-transferase gene variant and functional characterization of its retinoic acid response elements. J Biol Chem. 1997; 272(52): 3274332749.

[9] Ahlemeyer B, Bauerbach E, Plath M, Steuber M, Heers C, F Tegtmeier, J Krieglstein. Retinoic acid reduces apoptosis and oxidative stress by preservation of SOD protein level. Free Radic Biol Med. 2001; 30(10): 10671077.

[10] Kartha VN, S. Krishnamurthy. Antioxidant function of vitamin A. Int J Vitam Nutr Res. 1977; 47(4): 394-401.

[11] Melin AM, Carbonneau MA, Thomas MJ, Maviel MJ, Perromat A, Clerc M. Relationship between dietary retinol and alpha-tocopherol and lipid peroxidation in rat liver cytosol. Food Addit Contam. 1992; 9(1): 1-9.

[12] Datta PK, Lianos EA. Retinoic acids inhibit inducible nitric oxide synthase expression in mesangial cells. Kidney Int. 1999; 56(2): 486-493.

[13] Arroul-Lammali A, Rahal F, Chetouane R, Djeraba Z, Medjeber O, LadjouzeRezig A, Touil-Boukoffa C. Ex vivo alltrans retinoic acid modulates NO production and regulates IL-6 effect during rheumatoid arthritis: a study in Algerian patients. Immunopharmacol Immunotoxicol. 2017; 39(2): 87-96.

[14] Gatica L, Alvarez S, Gomez N, Zago MP, Oteiza P, Oliveros L, Gimenez MS. Vitamin A deficiency induces prooxidant environment and inflammation in rat aorta. Free Radic Res. 2005; 39(6): 621-628.

[15] Gatica LV, Oliveros LB, Pérez Díaz MF, Domínguez NS, Fornes MW, Gimenez MS. Implication of vitamin A deficiency on vascular injury related to inflammation and oxidative stress. Effects on the ultrastructure of rat aorta. Eur J Nutr. 2012; 51(1): 97-106.

[16] Wiseman EM, Bar-El Dadon S, Reifen R. The vicious cycle of vitamin A deficiency: a review. Critical Reviews in Food Science and Nutrition. 2016; 57 (17): 3703-3714. 
[17] Anzulovich AC, Oliveros LB, Muñoz E, Martínez LD, Giménez MS. Nutritional deficiency alters antioxidant defenses and modifies the liver histoachitecture. J Trace Elem Exp Med. 2000; 13: 343-357.

[18] Oliveros LB, Vega VA, Anzulovich AC, Ramírez DC, Giménez MS. Vitamin A deficiency modifies antioxidant defenses and essential element contents in rat heart. Nutr Res. 2000; 20: 1139-1150.

[19] Vasquez Gomez ME, Varas S, Gimenez MS. Model of long-term vitamin a deficiency in the mammary gland of virgin rats. Open Access Library Journal. 2017; 4: e3887.

[20] Neeld JB, Pearson WN. Macro and micro methods for the determination of vitamin A in serum using trifluoroacetic acid. Journal of Nutrition. 1963; 79: 454-462.

[21] Draper HH, Hadley M. Malondialdehyde determination as index of lipid peroxidation, Methods Enzymol. 1990; 186: 421-431.

[22] Winterbourn CC, Buss IH. Protein carbonyl measurement by enzyme-linked immunosorbent assay, Methods Enzymol. 1999; 300: 106-111.

[23] Weber D, Kneschke N, Grimm S, Bergheim I, Breusing N, Grune T. Rapid and sensitive determination of proteinnitrotyrosine by ELISA: application to human plasma. Free Radic Res. 2012; 46: 276-285.

[24] Puissant C, Houdebine LM. An improvement of the one-step method of RNA 29 isolation by extraction with guanidinium thiocyanate-phenol-chloroform acid. 30 Biotechniques. 1990; 8: 148-149.

[25] Rossi WM, Garrido G, Núñez Sellés AJ. Biomarkers of oxidative stress in antioxidant therapy. Journal of Pharmacy \& Pharmacognosy Research. 2016; 4(2): 62-83.

[26] Weber D, Stuetz W, Bernhard W, Franz A, Raith M, Grune T, Breusing N. Oxidative stress markers and micronutrients in maternal and cord blood in relation to neonatal outcome. European Journal of Clinical Nutrition. 2014; 68: 215-222.

[27] Tetik S, Kiliç A, Aksoy H, Rizaner N, Ahmad S, Yardimci T. Oxidative stress causes plasma protein modification. Indian J Exp Biol. 2015; 53(1): 25-30.

[28] Granot E, Kohen R. Oxidative stress in abetalipoproteinemia patients receiving long-term vitamin E and vitamin A supplementation. The American Journal of Clinical Nutrition. 2004; 79 (2), 226-230.

[29] de Oliveira MR. Review Article Vitamin A and Retinoids as Mitochondrial Toxicants. Oxidative Medicine and Cellular Longevity. 2015; Article ID 140267, 13.

[30] Esteban-Pretel G, Marin MP, Renau-Piqueras J, Barber T, Timoneda J. Vitamin A deficiency alters rat lung alveolar basement membrane: reversibility by retinoic acid. J Nutr Biochem. 2010; 21(3), 227-236.

[31] Barber T, Borras E, Torres L, Garcia C, Cabezuelo F, Lloret et al. Vitamin A deficiency causes oxidative damage to liver mitochondria in rats. Free Radic Biol Med. 2000; 29(1): 1-7.

[32] Ravi Kumar S, Narayan B, Vallikannan B. Fucoxanthin restrains oxidative stress induced by retinol deficiency through modulation of $\mathrm{Na}(+) \mathrm{K}(+)$-ATPase [corrected] and antioxidant enzyme activities in rats. Eur J Nutr. 2008; 47(8): 432-441.

[33] Sangeetha RK, Bhaskar N, Baskaran V. Comparative effects of beta-carotene and fucoxanthin on retinol deficiency induced oxidative stress in rats. Mol Cell Biochem. 2009; 331(1-2), 59-67.

[34] Zhou D, Zaiger G, Ghebremeskel K, Crawford MA and Reifen R. Vitamin A deficiency reduces liver and colon docosahexaenoic acid levels in rats fed high linoleic and low alpha-linolenic acid diet. Prostaglandins Leukot Essent Fatty Acids. 2004; 71(6): 383-389.

[35] Fonzo LS, Golini RS, Delgado SM, Ponce IT, Bonomi MR, Rezza IG, Anzulovich AC. Temporal patterns of lipoperoxidation and antioxidant enzymes are modified in the hippocampus of vitamin A-deficient rats. Hippocampus. 2009; 19(9): 869-880.

[36] Azevedo PS, Minicucci MF, Chiuso-Minicucci F, Justulin LA, Matsubara LS, Matsubara BB, Paiva SA. Ventricular remodeling induced by tissue vitamin A deficiency in rats. Cell Physiol Biochem. 2010; 26(3), 395-402.

[37] Li J, Cai X, Xia Q, Yao K, Chen J, Zhang Y, Wu Y. Involvement of endoplasmic reticulum stress in all-trans-retinalinduced retinal pigment epithelium degeneration. Toxicol Sci. 2015; 143(1), 196-208.

[38] Zhao F, Wu T, Lau A, Jiang T, Huang Z, Wang XJ, Zhang DD. Nrf2 promotes neuronal cell differentiation. Free Radic Biol Med. 2009; 47(6): 867-879. 
[39] Tan KP, Kosuge K, Yang M, Ito S. NRF2 as a determinant of cellular resistance in retinoic acid cytotoxicity. Free Radic Biol Med. 2008; 45(12): 1663-1673.

[40] James ML, Ross AC, Nicola T, Steele C, Ambalavanan N. VARA atenúa el desarrollo alveolar y la función pulmonar deteriorados inducidos por la hiperoxia en ratones recién nacidos. Am J Physiol Células Pulmonares Mol Physiol. 2013; 304 (11): L803 - L812.

[41] Wang G, Xiu P, Li F, Xin C, Li K. Vitamin A supplementation alleviates extrahepatic cholestasis liver injury through Nrf2 activation. Oxid Med Cell Longev. 2014; 273692.

[42] Balmus G, Karp NA, Ng BL, Jackson SP, Adams DJ, McIntyre RE. A high-throughput in vivo micronucleus assay for genome instability screening in mice. Nat Protoc. 2015; 10(1): 205-215.

[43] Connelly L, Palacios-Callender M, Ameixa C, Moncada S, Hobbs AJ. Biphasic regulation of NF-kappa B activity underlies the pro- and anti-inflammatory actions of nitric oxide. J Immunol. 2001; 166(6): 3873-3881.

[44] Gow A, Duran D, Thom SR, Ischiropoulos H. Carbon dioxide enhancement of peroxynitrite-mediated protein tyrosine nitration. Arch Biochem Biophys. 1996; 333: 42-48.

[45] Beckman JS, Ye YZ, Anderson PG, Chen J, Accavitti MA, Tarpey MM et al. Extensive nitration of protein tyrosines in human atherosclerosis detected by immunohistochemistry. Biol Chem Hoppe Seyler. 1994; 375: 81-88.

[46] Kmieć Z. Cooperation of liver cells in health and disease. Berlin; New York, Springer. 2001.

[47] Qiu H, Wu Y, Wang Q, Liu C, Xue L, Wang H, Jiang Q. Effect of berberine on PPARalpha-NO signalling pathway in vascular smooth muscle cell proliferation induced by angiotensin IV. Pharm Biol. 2007; 55(1): $227-232$.

[48] Vega VA, Anzulovich AC, Varas SM, Bonomi MR, Gimenez MS, Oliveros LB. Effect of nutritional vitamin A deficiency on lipid metabolism in the rat heart: Its relation to PPAR gene expression. Nutrition. 2009; 25(7-8): 828-838. 